\title{
EDUCAÇÃO DO CAMPO: CONTRIBUIÇÕES PARA O ESTADO DA ARTE DA PRODUÇÃO CIENTÍFICA (2007-2015)
}

\author{
Taisa Grasiela Gomes Liduenha Gonçalves* \\ Maria Cristina Piumbato Innocentini Hayashi**
}

\begin{abstract}
RESUMO
Orientada pela tríade “campo, educação e políticas públicas”, a Educação do Campo é um fenômeno concreto recente da realidade brasileira. Este artigo analisa a produção científica sobre o tema da Educação do Campo presente na agenda de pesquisas acadêmicas consolidada em artigos científicos disponíveis nas bibliotecas eletrônicas SciELO e Educ@. Do ponto de vista metodológico, o estudo está ancorado na abordagem bibliométrica e na análise de conteúdo dos artigos. Os resultados obtidos mostraram que a literatura científica publicada abrange o período entre 2007 e 2015, e que os principais temas tratados nos artigos são: políticas públicas, formação de educadores de campo, multisseriação, história da educação do campo, currículo, desenvolvimento, ensino de ciências, movimentos sociais e juventude, e trabalho e educação.
\end{abstract}

Palavras-chave: Educação do Campo. Estado da arte. Produção científica. Bibliometria.

\begin{abstract}
RURAL EDUCATION: CONTRIBUTIONS TO THE STATE OF THE ART OF SCIENTIFIC PRODUCTION (2007-2015)

Guided by the triad "countryside, education and public policy", the Rural Education is a recent concrete phenomenon of the Brazilian reality. This article analyzes the scientific literature on the subject rural education in academic research agenda composed of scientific articles published between 2007 and 2015 in the electronic library SciELO and Educ@ (Carlos Chagas Foundation). From a methodological point of view the study is anchored in bibliometric approach and content analysis of the articles. The results show that after almost two decades since the beginning of the struggles undertaken by the social movements and the establishment of regulatory frameworks of Rural Education, the main issues discussed in the articles are: public policies, training
\end{abstract}

* Doutora em Educação Especial pela Universidade Federal de São Carlos (UFSCar). Docente do Programa de Mestrado em Metodologias para o Ensino de Linguagens e suas Tecnologias na Universidade Norte do Paraná (UNOPAR). Pós-doutora (CAPES) no Programa de Pós-Graduação em Educação da Universidade Estadual de Londrina (UEL). Endereço para correspondência: Av. São Paulo, 926, ap. 204 - Centro. CEP: 86010-060. Londrina-PR. E-mail: taisaliduenha@gmail.com

** Doutora em Educação pela Universidade Federal de São Carlos (UFSCar). Professora Titular em Ciência da Informação e docente dos Programas de Pós-Graduação em Educação (PPGE), Educação Especial (PPGEEs) e Ciência, Tecnologia e Sociedade (PPGCTS) da Universidade Federal de São Carlos (UFSCar). Bolsista produtividade em pesquisa do CNPq. Endereço para correspondência: Rodovia Washington Luis, km 235. CEP: 13565-905. São Carlos-SP. E-mail: dmch@ufscar.br 
of rural educators, multi-grade, history of rural education, curriculum, development, science education, social movements and youth, and work and education.

Keywords: Rural Education. State of art. Scientific Production. Bibliometrics.

\section{RESUMEN}

\section{LA EDUCACIÓN DE CAMPO: CONTRIBUCIONES AL ESTADO DE ARTE DE LA PRODUCCIÓN CIENTÍFICA (2007-2015)}

Guiada por la tríada "campo, educación y política pública", la Educación de Campo es un fenómeno concreto reciente de la realidad brasilera. Este artículo analiza la producción científica sobre el tema Educación de Campo presente en la agenda de investigación académica consolidada en artículos científicos disponibles en las bibliotecas electrónicas SciELO y Educ@. Desde un punto de vista metodológico, el estudio está anclado en el enfoque bibliométrico y en el análisis del contenido de los artículos. Los resultados mostraron que la literatura científica publicada abarca el período entre 2007 y 2015, y que los principales temas recogidos en los artículos son: políticas públicas, formación de educadores rurales, multigrado, la historia de la educación del campo, el desarrollo curricular, la enseñanza de la ciencia, los movimientos sociales y la juventud, el trabajo y la educación.

Palabras clave: Educación del campo. Estado de arte. Producción científica. Bibliometría.

\section{Introdução}

Historicamente, a concentração da terra no Brasil advém de um processo de tensão em meio à violência contra os povos camponeses em prol da formação de latifúndio, em um contexto de desigualdade social. Em cinco séculos de sua história, o país vivencia a luta pela terra conduzida pelos camponeses, que resistem contra a expropriação e objetivam entrar na terra. Simultaneamente, ocorre a intensificação da concentração fundiária em nosso país (FERNANDES, 1999). Nesse contexto, conforme argumentam Santos, Paludo e Bastos (2010, p. 50), “a educação das pessoas do campo foi tomada como algo menor e sem importância", e a Educação Rural foi concebida considerando o campo enquanto um lugar de inferioridade e atraso. Na visão de Ribeiro (2012a, p. 299), a "Educação Rural funcionou como um instrumento formador tanto de uma mão de obra disciplinada para o trabalho assalariado rural quanto de consumidores dos produtos agropecuários gerados pelo modelo agrícola importado". Em 2011, o tema "Educação do Campo" foi alvo de análises em artigos de especialistas no volume temático do periódico Em Aberto, publicado pelo Inep e organizado por Mônica Castagno Molina (2011). A organizadora também elaborou uma "Bibliografia comentada" sobre o tema composta por uma seleção de livros e capítulos de livros, dissertações e teses, além de dois artigos que evidenciavam o surgimento e a consolidação da Educação do Campo.

Buscando inspiração nesse trabalho de Molina (2011), fomos instigadas a investigar como a temática da "Educação do Campo" vem sendo discutida no âmbito acadêmico passados quase 20 anos desde o início das lutas empreendidas pelos movimentos sociais e do estabelecimento dos marcos institucionais da Educação do Campo. No entanto, ao contrário do estudo de Molina (2011), que tomou como objeto de estudo os livros e capítulos, a pesquisa realizada se propôs a identificar e analisar a produção científica acadêmica sobre Educação do Campo consolidada em artigos publicados em periódicos científicos. 
Além dessa introdução e das conclusões, o texto é composto por tópicos que expõem um breve histórico da Educação do Campo no Brasil, o percurso metodológico da pesquisa e os resultados obtidos, além de uma lista final das referências citadas e dos artigos analisados.

\section{Panorama histórico da Educação do Campo no Brasil}

Santos, Paludo e Bastos (2010) explicam que a Educação do Campo contrapõe-se ao modelo de Educação Rural. Por sua vez, Caldart (2012) elucida que a expressão "Educação do Campo" nasceu a partir da denominação "Educação Básica do Campo" no contexto de preparação da I Conferência Nacional por uma Educação Básica do Campo, realizada de 27 a 30 de julho de 1998, em Luziânia, no estado de Goiás.

Vale a pena, portanto, historiar o momento de constituição da Educação do Campo no seio dos movimentos sociais, sobretudo das ações do Movimento dos Trabalhadores Sem Terra (MST) que foram essenciais para a elaboração de uma Educação do Campo porque buscaram, ao longo de sua história e lutas, a garantia do direito à educação, para que possam se instrumentalizar e, assim, intervir na realidade.

Conforme argumenta Molina (2003), a luta contra estrutura fundiária e política agrícola está engendrada ao contexto educacional do campo, e a partir dessa concepção é que se deu o nome de Conferência por uma Educação Básica do Campo, no sentido de uma luta contínua na construção de um novo projeto para o campo e para a educação. A autora enfatiza que a luta pela educação de qualidade no campo está atrelada ao "espaço de vida e de produção dos povos trabalhadores do campo" (MOLINA, 2003, p. 65), traduzindo o anseio de uma nação pautada na igualdade e justiça a todos os cidadãos brasileiros.

Em 1997, o MST promoveu o I Encontro Nacional das Educadoras e Educadores da Reforma Agrária (Enera) em parceria com a Universidade de Brasília, Fundo das Nações Unidas para a Infância (Unicef), Organizações das Nações Unidas para Educação, Ciência e Cultura (Unesco) e Conferência Nacional dos Bispos do Brasil (CNBB).
Participaram desse encontro cerca de 700 pessoas, sendo a maioria de educadores assentados e acampados e representantes universitários que apoiam o movimento. O objetivo do encontro foi avaliar o trabalho do Setor da Educação do MST e discutir sobre questões mais amplas da educação em áreas rurais brasileiras, tendo como eixo central os problemas econômicos, sociais e educacionais de acampamentos e assentamentos.

Naquele momento, entre os anos de 1997 e 1998, na vigência do governo Fernando Henrique Cardoso - ou governo FHC como é comumente referido -, com o financiamento do Banco Mundial tinha início no Brasil o Programa Escola Ativa (PEA). De acordo com seus pressupostos, o PEA busca melhorar a qualidade do desempenho escolar em classes multisseriadas das escolas do campo. Entre as principais estratégias estão: implantar nas escolas recursos pedagógicos que estimulem a construção do conhecimento do aluno e capacitar professores.

O Programa nasceu de uma proposta criada na Colômbia em 1975, no período de ditadura em toda a América Latina, e em contradição com as propostas da Educação do Campo não foi elaborado coletivamente, com a participação dos movimentos sociais. Inicialmente, esse Programa foi direcionado para as regiões que apresentavam maiores índices de analfabetismo no campo e onde se concentravam os conflitos de terra: Norte, Nordeste e Centro-Oeste (BEZERRA; BEZERRA NETO; LIMA, 2011; RIBEIRO, 2013a).

Estudos iniciados no governo FHC e consolidados no governo Lula, analisando o desenvolvimento do PEA no Brasil, mostraram que não houve avanços significativos na situação das escolas e na aprendizagem dos alunos do campo. D'Agostini, Taffarel e Santos Júnior (2012, p. 320) apontam que "a estrutura, a fundamentação teórica e a metodologia do programa não garantiram até o momento qualidade de ensino e efetivação da aprendizagem".

Em 16 de abril de 1998, criou-se o Programa Nacional de Educação na Reforma Agrária (Pronera), instituído pelo governo federal. É inegável a relevância do Enera para a constituição de uma das primeiras políticas públicas de Educação do Campo, o Pronera (CALDART, 2012; MOLINA, 2003).

Conforme assinalado por Bezerra Neto e Bezerra (2011), a criação de vários cursos do Pronera 
- Educação de Jovens e Adultos (EJA); Formação Continuada de Professores; Formação Profissional de Nível Técnico; Formação Profissional de Nível Superior (BRASIL, 2004) - visava minimizar as dificuldades enfrentadas pela população rural com relação ao acesso a educação, conforme apontaram os dados do censo agropecuário do IBGE.

Após a I Conferência Nacional por uma Educação Básica do Campo, ocorrida em 1998, vários estados continuaram trabalhando coletivamente os assuntos educacionais, e os movimentos discutiam as propostas da Conferência. Além disso, houve uma "Articulação Nacional por uma Educação Básica do Campo", que tinha como objetivo construir políticas públicas para as demandas educacionais do campo vinculadas ao desenvolvimento humano. Essa "Articulação tem forçado não só a uma ampliação da própria concepção do direito à educação, quanto uma amplitude do que, além de direito, se converta num dever do Estado" (MOLINA, 2003, p. 66).

De 2004, quando foi realizada a II Conferência Nacional por uma Educação do Campo, até os dias atuais, a Educação do Campo apresenta uma trajetória de contradições, entrelaçadas entre: campo, educação e políticas públicas. Contudo, na visão de Caldart (2012) é possível afirmar que houve avanços com relação às políticas, práticas e programas educacionais no campo, embora haja um enfretamento constante contra as políticas neoliberais na educação e na agricultura.

Em 2010, especifica-se a Educação do Campo enquanto política, destinada aos agricultores familiares, extrativistas, pescadores artesanais, ribeirinhos, assentados e acampados da reforma agrária, trabalhadores assalariados rurais, quilombolas, caiçaras, povos da floresta, caboclos e outros que produzem suas condições materiais de existência a partir do trabalho no meio rural. A política de Educação do Campo compromete-se a ampliar e qualificar a oferta de educação básica e superior às populações do campo (BRASIL, 2010).

Entretanto, o direito educacional, que deveria ser universal, vem se constituindo de forma focal, separando por grupos, conforme aponta Cury (2005). Essa fragmentação política, estratégia do sistema capitalista, faz com que cada grupo reivindique por uma especificidade, e, assim, perde-se a ideia de educação enquanto um todo.
Nesse breve histórico da Educação do Campo no Brasil constatamos que as conquistas da Educação do Campo foram concretizadas com muita luta, diante de um contexto econômico, político e social tão desigual como é o do nosso país.

\section{Percurso metodológico}

Optou-se pelo estudo bibliométrico, por possibilitar a construção de indicadores destinados a analisar a produção científica. De acordo com Silva, Hayashi e Hayashi (2011, p. 113-114), “a análise bibliométrica é um método flexível para avaliar a tipologia, a quantidade e a qualidade das fontes de informação citadas em pesquisas". Esse recurso metodológico permite construir indicadores de produção científica, os quais, mediante uma análise crítica e aprofundada, permitem traçar um panorama do estado da arte dos temas de interesse pesquisados. Combinada com outras metodologias, como a análise de conteúdo, a análise bibliométrica se fortalece, pois permite perscrutar a própria substância dos textos analisados. Mediante esse entendimento, ambas as abordagens foram adotadas neste artigo.

As fontes de dados da pesquisa foram as bibliotecas eletrônicas SciELO e Educ@, que disponibilizam, por meio de acesso livre, coleções de periódicos científicos brasileiros. A escolha dessas bases de dados científicas justifica-se pela sua abrangência. A coleção SciELO apresenta 286 títulos de periódicos, dos quais 87 são da área de Ciências Humanas, enquanto que a Educ@ é uma biblioteca eletrônica organizada pela Fundação Carlos Chagas, reunindo 36 títulos de periódicos da área de Educação (SCIELO, 2015; EDUC@, 2015)

Para a coleta de dados utilizou-se o método de busca simples por assunto com a expressão "educação do campo", que foi extraída da literatura científica que embasou a pesquisa. Para o registro dos dados coletados foram utilizados protocolos de registro de dados bibliométricos elaborado por Hayashi e colaboradores (2011) no formato de uma planilha Excel, ${ }^{\circledR}$ com campos específicos, tais como: base de dados, autor(es), referência completa, ano de publicação, título do periódico, resumo, palavras-chave, entre outros. 
Foi definido como critério de inclusão os trabalhos disponíveis na SciELO e na Educ@, independente de um período temporal pré-estabelecido, pois a intenção foi mapear a evolução da produção científica sobre esse tema. Os dados foram coletados em maio de 2015, e o resultado inicial dessa coleta apontou a existência de 45 trabalhos publicados entre 2007 e 2015. Excluídos os trabalhos repetidos $(\mathrm{n}=7)$, o corpus final foi composto por 38 artigos. A biblioteca eletrônica SciELO foi a que apresentou o menor porcentagem $(15,7 \%)$ de registros $(n=9)$, sendo que $23,8 \%(n=6)$ do total estava disponível em ambas as bases de dados. Justificam-se os maiores escores $(n=23)$ para a base Educ@ pelo fato de ser uma biblioteca eletrônica de periódicos especializada na área de Educação.

\section{Panorama bibliométrico das pesquisas}

Inicialmente, apresentamos os principais indicadores da produção científica analisada: total de registros por base de dados, distribuição temporal dos trabalhos, títulos dos periódicos que publicaram os artigos, autoria e coautorias. Em seguida, aprofundamos a análise com a identificação e categorização das temáticas abordadas nos artigos, complementando-a com uma síntese dos trabalhos. Em relação à distribuição temporal, os 38 artigos (Figura 1) foram publicados no período compreendido entre 2007 e 2015.

Figura 1 - Distribuição temporal dos 38 artigos analisados

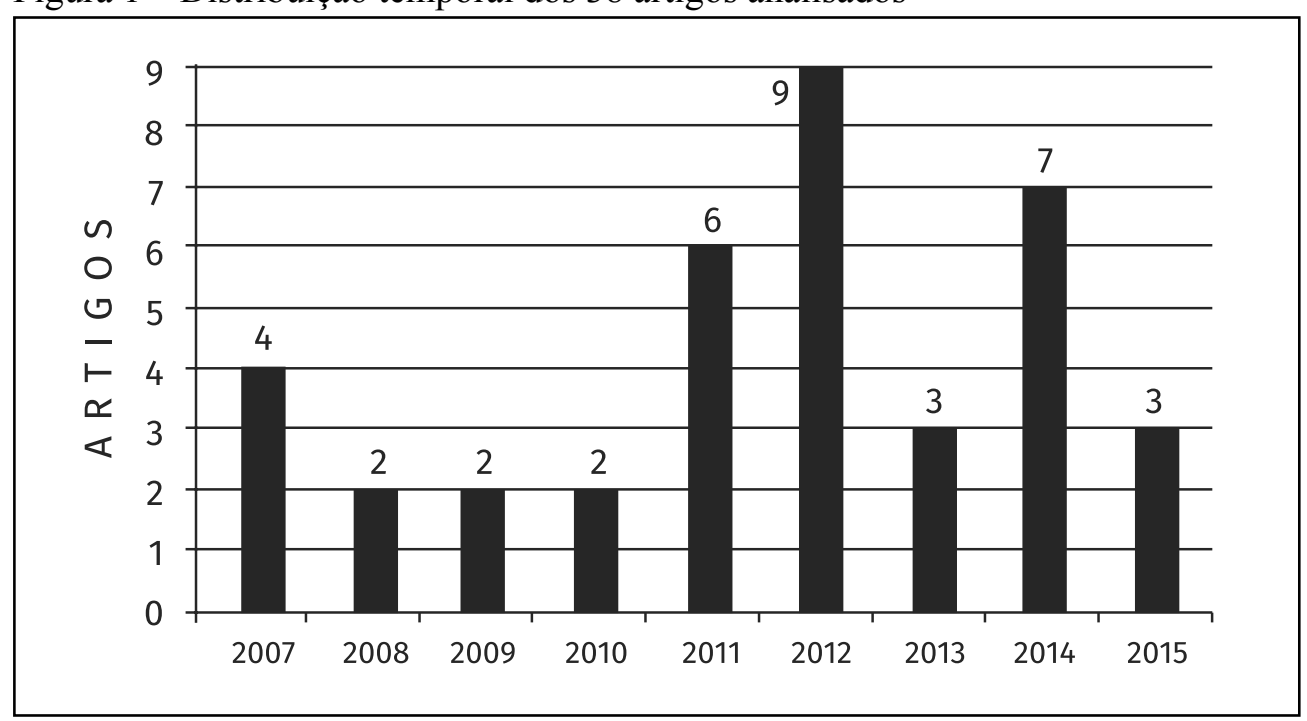

Fonte: Elaborado pelas autoras deste artigo.

Os dados da Figura 1 mostram que antes de 2007 não foram encontrados artigos sobre o tema da Educação do Campo, indicando que a produção científica sobre a temática nessas bases de dados é recente, cobrindo um período de nove anos, com poucas oscilações e crescimento acentuado nos anos de 2012 e 2014.

A pesquisa realizada também traçou um perfil dos periódicos que publicaram os 38 artigos analisados. Foram investigados títulos e instituições publicadoras dos periódicos, além da classificação de cada um na lista Qualis/Capes elaborada pela
Capes. Nessa lista, os periódicos são classificados em oito estratos (A1, A2, B1, B2, B3, B4, B5 e C), sendo que os quatro primeiros são considerados os mais altos. Apesar das controvérsias que geram na comunidade científica, tais índices são amplamente utilizados para fins de estratificação da qualidade da produção intelectual dos programas de pós-graduação no país. Os resultados podem ser visualizados na Tabela 1, que relaciona os 22 títulos dos periódicos e o total de artigos publicados sobre a temática "Educação do Campo" em cada um deles. 
Tabela 1 - Periódicos, instituições publicadoras e classificação Qualis/Capes

\begin{tabular}{|c|c|c|}
\hline Periódicos e Instituições publicadoras & $\begin{array}{l}\text { Total de } \\
\text { Artigos }\end{array}$ & $\begin{array}{l}\text { Classificação } \\
\text { Qualis/CAPES }\end{array}$ \\
\hline Roteiro (UNOESC) & 3 & B2 \\
\hline Revista Diálogo Educacional (PUC-PR) & 3 & $\mathrm{~A} 2$ \\
\hline Revista de Educação Pública (UFMT) & 3 & A2 \\
\hline Educação (UFSM) & 3 & B1 \\
\hline Revista da FAEEBA (UNEB) & 2 & $\mathrm{~A} 2$ \\
\hline Praxis Educativa (UEPG) & 2 & $\mathrm{~A} 2$ \\
\hline Ensaio: Avaliação e Políticas Públicas em Educação (CESGRANRIO) & 2 & A1 \\
\hline Educar em Revista (UFPR) & 2 & A1 \\
\hline Educação em Revista (UFMG) & 2 & A1 \\
\hline Educação e Pesquisa (FE-USP) & 2 & A1 \\
\hline Educação \& Sociedade (CEDES) & 2 & $\mathrm{~A} 1$ \\
\hline Cadernos CEDES & 2 & $\mathrm{~A} 2$ \\
\hline Revista de Educação (PUC-Campinas) & 1 & B2 \\
\hline Revista Brasileira de História da Educação (SBHE) & 1 & $\mathrm{~A} 2$ \\
\hline Revista Brasileira de Estudos Pedagógicos (INEP) & 1 & B1 \\
\hline Revista Brasileira de Educação (ANPED) & 1 & $\mathrm{~A} 1$ \\
\hline Perspectiva (UFSC) & 1 & $\mathrm{~A} 2$ \\
\hline Linhas Críticas (UnB) & 1 & B1 \\
\hline Interações (UCDB) & 1 & B2 \\
\hline Educação: Teoria e Prática (UNESP/Rio Claro) & 1 & B2 \\
\hline Educação (PUCRS) & 1 & $\mathrm{~A} 2$ \\
\hline Contrapontos (UNIVALI) & 1 & B1 \\
\hline
\end{tabular}

Fonte: Elaborado pelas autoras deste artigo.

A maioria $(\mathrm{n}=16)$ dos periódicos é publicada por instituições vinculadas a universidades (públicas, particulares e confessionais), enquanto nos demais periódicos a responsabilidade é de associações acadêmicas (Sociedade Brasileira de História da Educação - SBHE e Associação Nacional de Pós-Graduação e Pesquisa em Educação - ANPEd); órgão ministerial (Instituto Nacional de Estudos e Pesquisas Educacionais Anísio Teixeira - INEP); instituição educacional que atua na área de concursos públicos, vestibulares, capacitação e projetos sociais e culturais (Fundação Cesgranrio) e uma organização não governamental que desenvolve estudos e pesquisas na área de educação e sociedade (Centro de Estudos Educação e Sociedade-Cedes). Além disso, as instituições sedes desses periódicos estão situadas na região $\operatorname{Sul}(n=9)$, Sudeste $(n=8)$,
Centro-Oeste $(n=4)$ e Nordeste $(n=1)$ do país.

De acordo com a Tabela 1, quatro periódicos concentraram o maior número de artigos cada $(n=4)$, totalizando $31,6 \%$ dos artigos: Roteiro (UNOESC), Revista Diálogo Educacional (PUC-PR), Revista de Educação Pública (UFMT) e Educação (UFSM). Por sua vez, oito periódicos publicaram dois artigos cada, representando juntos $42,1 \%(n=16)$ do total, enquanto os demais periódicos $(\mathrm{n}=10)$ publicaram apenas um artigo cada, perfazendo $26,3 \%$ do total publicado.

Em relação à classificação Qualis/Capes, todos os periódicos pertencem aos estratos mais elevados: $\mathrm{A} 1=6 ; \mathrm{A} 2=8 ; \mathrm{B} 1=4$ e $\mathrm{B} 2=4$, sendo que $68,4 \%$ $(n=26)$ dos artigos foram publicados em 14 periódicos classificados como A1 ( $n=11)$ e A2 $(n=15)$, enquanto os demais periódicos $(n=8)$ classificados 
como B1 e B2 publicaram $31,6 \%(n=12)$ do total de artigos.

As autorias dos 38 artigos também foi objeto de análise, e os resultados indicaram que 53 autores estiveram envolvidos nas autorias e coautorias dos artigos (Figura 2).

Figura 2 - Distribuição das autorias e coautorias dos artigos

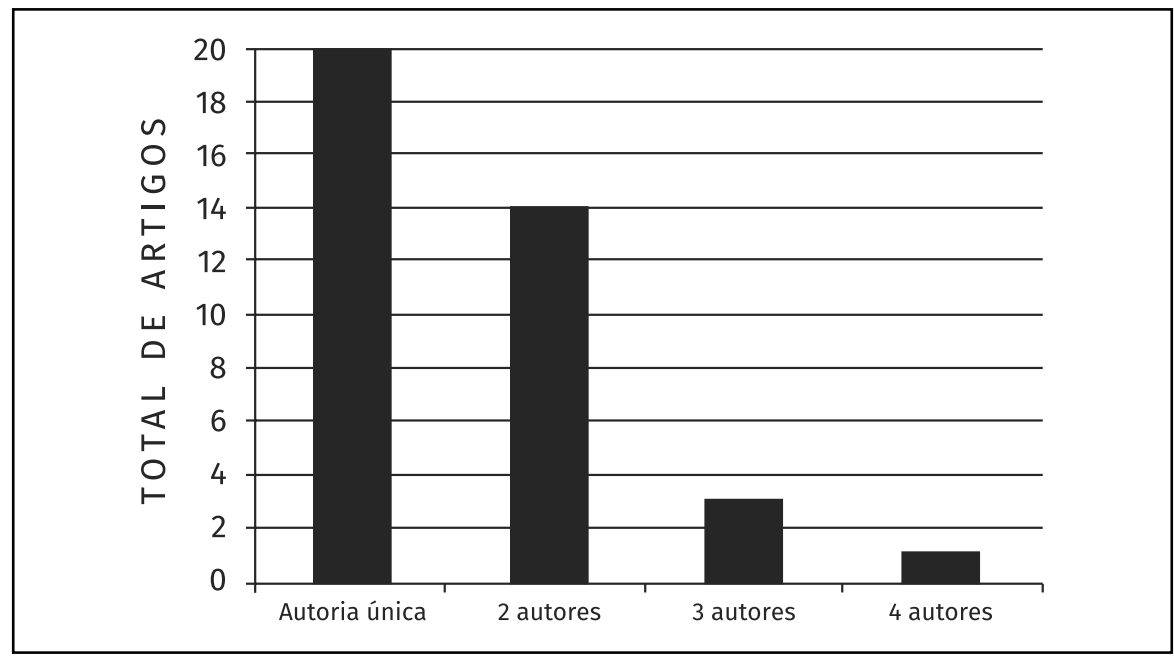

Fonte: Elaborado pelas autoras deste artigo.

A Figura 2 mostra que as coautorias com dois autores totalizaram $36,8 \%$ dos artigos $(n=14)$, seguidas pelas coautorias com três autores, perfazendo $7,9 \%$ do total de artigos $(n=3)$. A coautoria de quatro autores foi identificada em apenas um artigo. É válido mencionar que as coautorias podem remeter a um trabalho interdisciplinar reunindo olhares diferentes sobre a Educação do Campo.

Os dados da Figura 2 mostram que não há grandes discrepâncias em relação ao tipo de autoria, uma vez que $52,6 \%(n=20)$ dos artigos são de autoria única, enquanto os artigos escritos em coautoria totalizaram $47,4 \%(n=17)$. No entanto, quando comparamos os resultados da Figura $3 \mathrm{com}$ os trabalhos apresentados no II Encontro Nacional de Pesquisa em Educação do Campo (MOLINA, 2010), verificamos que, embora invertidos, os escores das autorias $(45,7 \%)$ e coautorias $(54,3 \%)$ também são semelhantes.

Ainda em relação às análises das autorias, estas revelaram que entre os 38 artigos, quatro pesquisadores contribuíram com mais de um artigo (Figura 3).

Figura 3 - Autores com mais artigos publicados

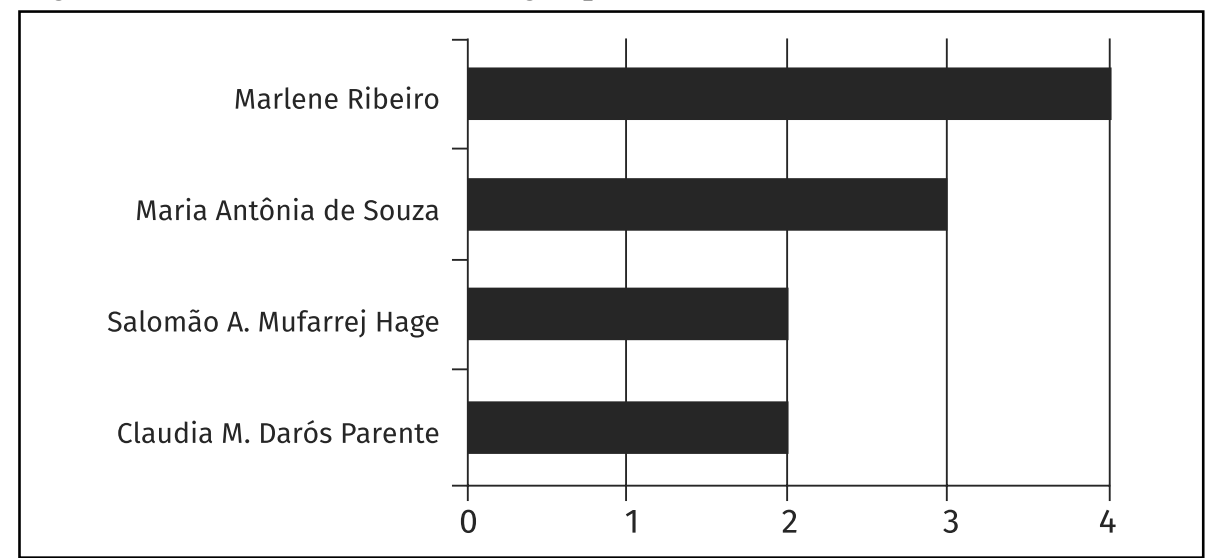

Fonte: Elaborado pelas autoras deste artigo. 
Os achados da Figura 3 sugerem a constituição de expertise em relação à temática da Educação do Campo. Em reforço a esse argumento, consultamos o Diretório de Grupos de Pesquisa no Brasil/CNPq e observamos que dois desses pesquisadores são líderes de grupos de pesquisa dedicados à temática: Salomão A. Mufarrej Hage lidera o "Grupo de Estudo e Pesquisa em Educação do Campo na Amazônia"; Maria Antônia de Souza lidera o grupo "Movimentos Sociais, Educação do Campo e Práticas Pedagógicas". Embora Marlene Ribeiro não lidere grupos de pesquisa com temática específica em Educação do Campo, o currículo da pesquisadora disponível na Plataforma Lattes demonstra expressiva produção científica de artigos, livros e capítulos, trabalhos em eventos, bem como desenvolvimento de pesquisas e orientações de teses e dissertações relacionadas ao tema. O currículo de Claudia da Mota Daros Parente também demonstra o desenvolvimento de pesquisas e publicações na área de Educação do Campo.

Outro sinal do reconhecimento da expertise na área pode ser dado pelo fato de que cinco autores dos artigos contribuíram com os seguintes verbetes no Dicionário de Educação do Campo (CALDART et al, 2012): "Escola Ativa" (Adriana D'Agostini, em coautoria com Celi Zulke Taffarel e Claudio de Lira Santos Júnior); "Educação Popular" (Conceição Paludo); "Movimento de Mulheres Camponesas no Brasil” (Conceição Paludo, em coautoria com Vanderlea Laodete Pulga Daron); "Agroecologia (Dominique Michèle Perioto Guhur, em coautoria com Nilciney Toná); "Educação Rural" e "Emancipação versus Cidadania" (Marlene Ribeiro); "Escola do Campo" e "Licenciatura em Educação do Campo" (Mônica Castagna Molina, em coautoria com Lais Mourão Sá); "Legislação Educacional do Campo" (Mônica Castagna Molina); "Política educacional e Educação do Campo" (Mônica Castagna Molina, em coautoria com Celi Zulke Taffarel); "Políticas Públicas" (Mônica Castagna Molina).

Em relação ao gênero dos 53 autores dos 38 artigos observou-se que $70 \%(n=37)$ são mulheres, enquanto os homens representam $30 \%(n=16)$ do total. Esses resultados sustentam os argumentos que em determinadas áreas de conhecimento ocorre o processo de feminização da ciência (RIGOLIN; HAYASHI; HAYASHI; 2013). Além disso, os achados da pesquisa não são diferentes daqueles encontrados em outras pesquisas da área de Educação (BITTAR; SILVA; HAYASHI, 2011), apontando a predominância do gênero feminino nesse campo de conhecimento.

As 128 palavras-chave atribuídas pelos autores dos 38 artigos foram agrupadas por meio do recurso gráfico denominado "nuvem de palavras" (Figura 4), que destaca as palavras em tamanhos maiores ou menores de acordo com a frequência no texto. Esse agrupamento oferece uma primeira aproximação às temáticas mais abordadas pelos artigos.

Figura 4 - Nuvem de palavras com as temáticas dos artigos

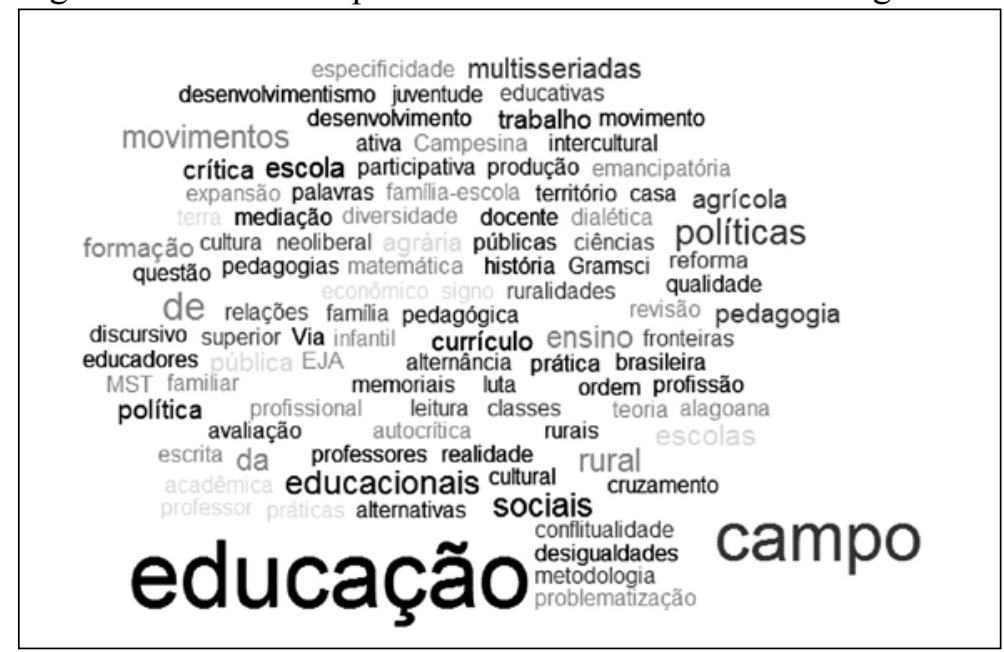

Fonte: Elaborado pelas autoras deste artigo. 


\section{O que dizem as pesquisas sobre Educação do Campo?}

Para analisar as pesquisas sobre "Educação do Campo" relatadas nos 38 artigos, optamos por estabelecer nove categorias temáticas (Figura 5).

Figura 5 - Total de artigos por categoria temática

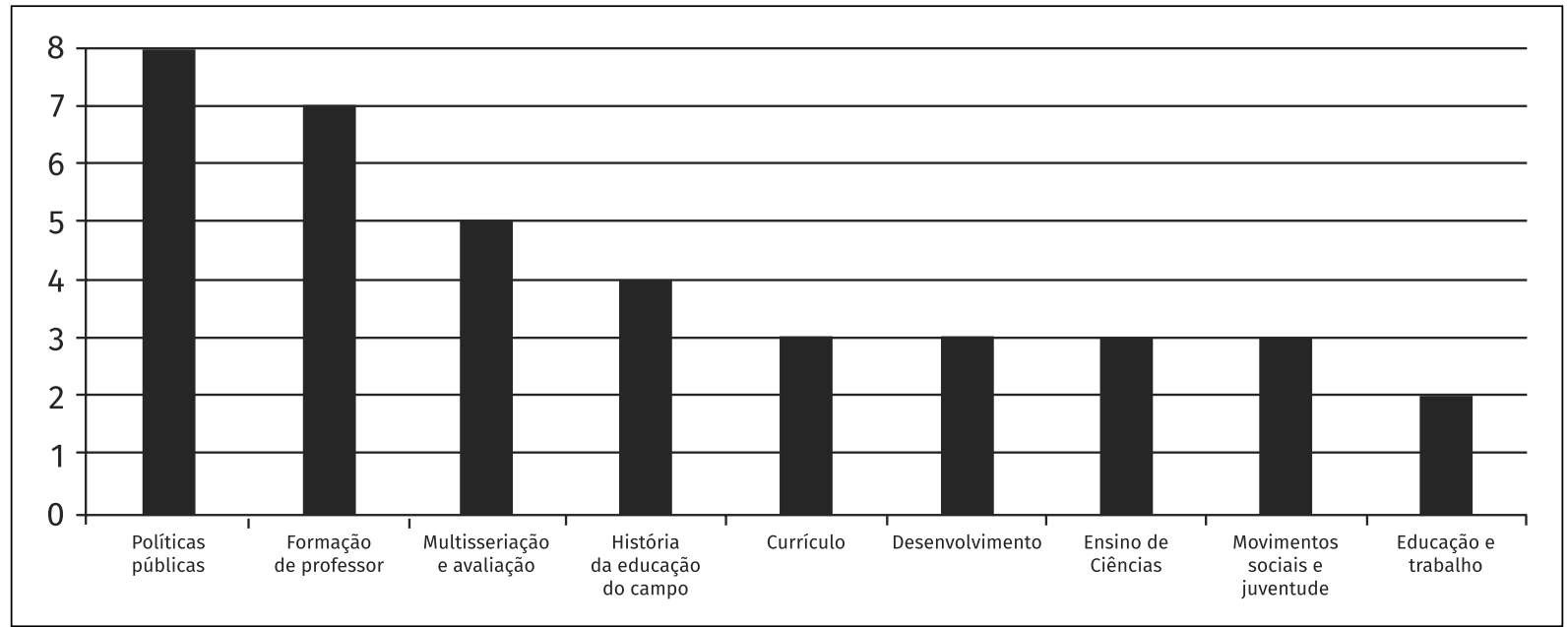

Fonte: Elaborado pelas autoras deste artigo.

Essas categorias foram estabelecidas após a leitura integral dos artigos e mediante a literatura científica que embasou a pesquisa. Confrontadas com os verbetes do Dicionário da Educação do Campo (CALDART et al, 2012) tais categorias per- mitiram compreender os fundamentos filosóficos e pedagógicos da Educação do Campo expressos nos artigos analisados. O Quadro 1 apresenta a distribuição dessas nove temáticas de acordo com os autores e ano de publicação.

Quadro 1 - Temáticas abordadas nos artigos

\begin{tabular}{|l|l|}
\hline TEMÁTICAS & \multicolumn{1}{|c|}{ AUTORES / ANO } \\
\hline Políticas Públicas & $\begin{array}{l}\text { Cavalcante (2010); Souza e Marcoccia (2011); D’Agostini (2012); Ribeiro (2012); } \\
\text { Marcon (2012); Ribeiro (2013b); Jesus (2015) }\end{array}$ \\
\hline Formação de Educadores & $\begin{array}{l}\text { Nascimento (2007); Casagrande (2008); Teixeira, Bernartt e Trindade (2008); } \\
\text { Gehrke (2009); Ribeiro (2013a); Correia e Rocha (2013); Molina (2015) }\end{array}$ \\
\hline Multisseriação e avaliação & Souza e Santos (2007); Machado (2010); Hage (2014); Parente (2014a; 2014b) \\
\hline História da Educação do Campo & Guhur e Silva (2009); Rangel e Carmo (2011); Paludo e Silveira (2014); Ribeiro (2015) \\
\hline Currículo & Antonio e Lucini (2007); Ribeiro e Paraíso (2012); Thiesen e Oliveira (2014) \\
\hline Desenvolvimento & Cêa, Silva e Silva (2014); Marschner (2011); Hidalgo (2012) \\
\hline Ensino de Ciências & Monteiro, Cruz e Alves (2012); Cruz e Szymanski (2012); Crepalde e Aguiar Jr. (2014) \\
\hline Movimentos Sociais e Juventude & Hage e Oliveira (2011); Verdério (2011); Rossi et al (2014) \\
\hline Trabalho e Educação & Vendramini (2007); Gonçalves e Silva (2011) \\
\hline
\end{tabular}

Fonte: Elaborado pelas autoras deste artigo. 
A seguir apresentamos as diferentes visões sobre a Educação do Campo expressas nos 38 artigos analisados, de acordo com as categorias temáticas estabelecidas. Contudo, como algumas categorias temáticas só abrangeram um artigo, a descrição destas foi agrupada com a de outras.

\section{Políticas Públicas de Educação do Campo}

A temática "políticas públicas" teve maior incidência, com $21 \%(n=8)$ entre os 38 artigos. Como explica Molina (2012, p. 453) ação do Estado para garantir direitos sociais "requer estratégias de intervenção na sociedade, por meio de programas que deem materialidade a estes direitos", o que implica em reconhecer na cena pública brasileira a presença de sujeitos coletivos de direito.

O estudo de Cavalcante (2010) discute a viabilidade das políticas de educação do campo no território rural brasileiro diante da lógica da produção capitalista, contrária à proposta de educação dos movimentos sociais.

Souza e Marcoccia (2011) problematizam a educação do campo, os aspectos da realidade das escolas públicas e as metas previstas no projeto do Plano Nacional de Educação (PNE 2011-2020). As autoras constataram que nos últimos anos as conquistas no plano educacional e político foram significativas, contudo há muitas propostas que foram discutidas na Conferência Nacional de Educação (Conae) que estão distantes do PNE, tais como: a transversalidade da educação do campo na educação básica e superior; a interface entre educação especial e educação do campo; a política pública de financiamento da educação do campo; e a gestão da educação da educação do campo. Destacamos que esse foi o único trabalho que fez referência aos alunos com deficiência que vivem no campo.

D’Agostini (2012) analisou a educação do campo no contexto educacional brasileiro a partir da década de 1990, devido ao desenvolvimento e à consolidação da educação do campo como política pública e como concepção pedagógica. A autora aponta que a proposição da educação do campo era contra as políticas educacionais neoliberais, com fins emancipadores, entretanto, ao longo desse processo, incorpora as contradições gerais entre trabalho e capital.

O artigo de Souza (2012) identificou a gênese da prática e concepção da educação do campo, atentando para a concentração da terra e da propriedade como elementos estruturais geradores de desigualdade social. Na visão da autora, a educação do campo originou-se com o intuito de interrogar os condicionantes estruturais históricos da sociedade brasileira, entre eles "a desigualdade educacional, os processos econômicos e políticos excludentes e a prática tecnocrática e patrimonialista de elaboração de políticas públicas” (SOUZA, 2012, p. 759).

Em outro estudo, Ribeiro (2012b) aponta as potencialidades da educação do campo enquanto conquista do Movimento Camponês e os limites que ela enfrenta em nosso país, em que o capital agrário e financeiro, relacionado ao agronegócio, disputa a propriedade da terra e exerce pressão sobre o Estado.

As diretrizes da educação do campo foram analisadas por Marcon (2012) numa dupla perspectiva: avanços e desafios. Os avanços evidenciam-se na formulação de diretrizes baseadas na concepção de educação emancipatória e cidadã, e os desafios, por sua vez, concretizam-se nas dificuldades da escola do campo em problematizar os contextos socioculturais dos seus alunos; na implementação de políticas de nucleação por governos estaduais e municipais que resultam no deslocamento de escolas do campo para as cidades ou pequenos povoados; e no transporte escolar.

As concepções que informam a educação do campo e o Programa Escola Ativa, no intuito de captar as contradições na política de Estado para a população da área rural, foram analisadas por Ribeiro (2013b). A autora aponta a reedição da Escola Nova identificada como Escola Ativa numa realidade e tempo diversos dos que lhes deram origem. Portanto, a aparência dessas políticas educacionais é materializada nas estratégias do Estado explicitadas nos documentos que orientam a aplicação da Escola Ativa e da educação do campo, e a essência é identificada pela relação custo-benefício, associada à retirada gradativa do Estado como financiador dessa política.

Por sua vez, as contradições da política pública de Educação do Campo em meio à luta pela 
Reforma Agrária dos trabalhadores rurais diante do projeto neoliberal do Governo Fernando Henrique Cardoso (1998-2002) e do Governo Lula da Silva (2003-2010) foram objeto de estudo de Jesus (2015). A autora faz um resgate histórico dos trabalhadores do campo na luta pelo direito à educação pública de qualidade e a parcialidade dos governos na estruturação de programas e de aprovação de marcos legais. A conclusão é que a Reforma Agrária não se materializou e a lógica do agronegócio dissemina no meio rural, inclusive na área educacional.

\section{Formação de educadores de campo}

Como refere Arroyo (2012b, p. 363), as contribuições da concepção de formação dos profissionais do campo para a formação de todo profissional da educação básica deve "reconhecer os saberes do trabalho, da terra, das experiências e das ações coletivas sociais e legitimar esses saberes como componentes teóricos dos currículos". Na visão do autor significa "romper com a qualificação instrumental e afirmar uma formação na qual a raiz de tudo é o ser humano, seu processo de humanização, de emancipação humana". Para tanto é necessário "superar a fragmentação do conhecimento e uma das estratégias para essa superação é a formação por áreas e não por disciplinas". (ARROYO, 2012a, p. 365).

Na pesquisa realizada, essa temática foi abordada em $21 \%(n=8)$ do total de 38 artigos analisados. Por exemplo, Nascimento (2007) buscou a contribuição do pensamento de Gramsci na elaboração e aplicação das pedagogias alternativas de educação do campo, sobretudo a dos Centros de Formação em Alternância.

Casagrande (2008) verificou a formação de educadores desenvolvida pelo Movimento dos Trabalhadores Rurais Sem Terra (MST) e Via Campesina Brasil, na segunda turma do curso de Pedagogia da Terra, realizado no Instituto Técnico de Capacitação e Pesquisa da Reforma Agrária (Iterra), no período de 2003 a 2007, em Veranópolis, Rio Grande do Sul. A autora conclui que apesar do curso Pedagogia da Terra sofrer as determinações sob a estrutura capitalista, tem apontado possibilidades de alteração do trato com o conhecimento e com a organização do trabalho pedagógico.

A Pedagogia da Alternância é uma proposta pedagógica de formação para os educadores do campo, organizada em diferentes espaços e com uma flexibilidade no tempo. Teixeira, Bernartt e Trindade (2008) realizaram um levantamento das dissertações de mestrado e teses de doutorado brasileiras sobre Pedagogia da Alternância defendidas entre 1969 e 2006 e verificaram um total de 46 trabalhos, sendo 7 teses e 39 dissertações; contudo, existem aspectos que merecem estudos mais aprofundados com relação a esta proposta pedagógica.

As percepções de licenciandas de Pedagogia do campus universitário de Rondonópolis da Universidade Federal de Mato Grosso sobre a constituição da identidade docente foram analisadas por Correia e Rocha (2013). Essas alunas eram oriundas da vida no/do campo e de assentamentos do MST. Os resultados mostram que as licenciandas compreendem que a função do professor é fundamental para a mudança da sociedade, apesar da mínima valorização que a esfera pública dá a este profissional. Desse modo, o estudo apontou a necessidade de políticas públicas direcionadas à Educação do Campo que valorizem o educador e que melhorem a educação pública do nosso país.

O estudo de Molina (2015) analisou a expansão da Educação Superior do Campo a partir do Programa Nacional de Educação do Campo (Pronacampo), que tem ações voltadas ao acesso e à permanência na escola, à aprendizagem e à valorização do universo cultural das populações do campo. Para a autora, a ampliação de novos cursos de Licenciatura em Educação do Campo pode ser considerada uma importante vitória dos movimentos sociais com relação à oferta de formação de educadores; a conquista dos fundos públicos do Estado para manutenção dessas graduações e institucionalização da Educação Superior em Alternância. Porém, essa expansão também impõe uma série de desafios à manutenção dos princípios originais do Movimento da Educação do Campo, tais como: as estratégias de ingresso dos sujeitos camponeses nas Licenciaturas; o protagonismo dos movimentos sociais; a vinculação com as Escolas do Campo; a concepção de Alternância a ser implementada nas Licenciaturas e a compreensão e 
execução da formação por área de conhecimento.

Ainda sobre a formação de Professores, Ribeiro (2013a) analisou essa temática estabelecendo interfaces com a Educação de Jovens e Adultos (EJA) e a Educação do Campo, indicando que cada uma possui suas especificidades, e indica a necessidade de serem articuladas na unidade da formação de educadores de EJA do campo. A autora aponta que embora isoladamente esses temas possuam uma razoável produção acadêmica, ainda há muito por fazer no que diz respeito a um tratamento integrado do tema.

A leitura e escrita na construção da educação do campo, sobretudo na formação de educadores do MST, foi abordada no artigo de Gehrke (2009). $\mathrm{O}$ autor apresenta ainda a prática de ler, escrever e trocar cartas da Escola Municipal Irmão Cirilo, do Assentamento Missões de Francisco Beltrão, Paraná. Em sua visão, essa atividade é relevante e transgressora no sentido da formação humana pretendida, fechando com os desafios que pedagogos têm e precisam assumir no trato com a leitura e a escrita na Escola do Campo. Desse ponto de vista, a discussão sobre leitura e escrita e o lugar que podem ocupar no ensino e na formação dos educadores do campo contribuirá no processo de escolarização das crianças camponesas.

\section{História da educação do campo}

Como referem Molina e Abreu (2011, p. 11) a Educação do Campo originou-se do processo de luta dos movimentos sociais camponeses comprometidos com "a construção de uma sociedade sem desigualdades, com justiça social". A história dessas lutas, que é parte integrante da história da educação do campo, é abordada em quatro artigos, tendo como contraponto a Reforma Agrária e as políticas públicas.

O estudo de Guhur e Silva (2009) aborda a origem e a trajetória dos sujeitos coletivos do campo, bem como seu papel na constituição de um movimento nacional que luta por políticas públicas para a Educação. Ao enfocarem o Programa Nacional de Educação na Reforma Agrária (Pronera), as Diretrizes Operacionais para a Educação Básica nas Escolas do Campo e as Escolas Itinerantes, as autoras mostram que a pedagogia do movimento resultou da reflexão teórica sobre o encontro entre educação e movimentos sociais.

O objetivo do estudo de Rangel e Carmo (2011) foi recuperar alguns eventos históricos da educação rural e o percurso de evolução de seu significado para a concepção social e politicamente mais ampla de educação do campo. As autoras indicam pouca atenção política ao contexto rural e suas escolas, cujo currículo e práticas têm sido submetidos ao modelo da escola urbana, e destacam a relevância histórica de movimentos sociopolíticos em prol da valorização dos sujeitos do meio rural, incluindo indígenas e remanescentes dos quilombos, reconhecendo a sua importância para a vida e a história do país.

Por sua vez, a história da educação infantil do campo no Brasil foi discutida no artigo de Paludo e Silveira (2014). Para tanto, as autoras retomaram a luta pelo direito à educação, impulsionada pelos movimentos sociais do campo, sobretudo o MST. As autoras concluem que a Educação Infantil do Campo teve forte influência da Educação Infantil e da Educação do Campo, com uma política pública que denuncia o silenciamento e esquecimento dos direitos negados para a população do campo.

Ribeiro (2015) aborda as conexões históricas da educação do campo que, no seu processo de construção, articula a reforma agrária ao trabalho camponês, sendo esse processo atravessado pelos conflitos entre as forças que representam o trabalho no campo, associadas à reforma agrária e à educação, e às forças que representam o capital, vinculado às grandes propriedades rurais e ao agronegócio.

\section{As escolas multisseriadas e a avaliação participativa na Educação do Campo}

A organização das escolas do campo é multisseriada, isto é, concentra em uma mesma sala de aula estudantes de níveis diferentes de apreensão de conhecimento. A justificativa para sua implantação desde o governo FHC, e que permanece nos governos Lula e Dilma, reside no argumento de que há enorme dispersão geográfica da moradia de estudantes em escolas pequenas, em locais de difícil acesso e de baixa densidade populacional, 
contando com apenas um professor. $\mathrm{Na}$ visão de D’Agostini, Taffarel e Santos Junior (2012, p. 315) essa realidade da educação do campo, apesar de polêmica e complexa, é "uma forma possível e necessária de organização escolar do campo e podem ser referência de qualidade de ensino se organizadas por ciclos e princípios multidisciplinares".

Dentre os 38 artigos analisados, foram identificados $13,1 \%(n=5)$ que discutem a multisseriação e a avaliação participativa nas escolas do campo.

A pesquisa de Souza e Santos (2007) analisou a prática pedagógica do professor que atua em uma sala multisseriada em uma escola de assentamento no estado do Paraná. Os autores constataram que a prática do professor não está dicotomizada da realidade socioeconômica dos seus alunos, havendo uma preocupação com a formação humana.

A crítica e autocrítica como proposta de avaliação participativa em duas escolas localizadas em assentamentos no estado do Mato Grosso foram analisadas no estudo de Machado (2010). O estudo adotou a abordagem da pesquisa participante, e os resultados mostram a valorização dessa avaliação crítica e participativa no contexto nas escolas de assentamento por propiciar uma educação transformadora e emancipatória.

Hage (2014), por sua vez, analisa a realidade das escolas rurais com turmas multisseriadas a partir dos resultados das pesquisas realizadas pelo Grupo de Estudo e Pesquisa em Educação do Campo na Amazônia. Na visão do autor, há um paradoxo entre o abandono e a precarização que caracteriza as condições dessas escolas e as ações criativas realizadas por professores e alunos no cotidiano escolar, apontando para a transgressão do paradigma seriado urbano de ensino atualmente hegemônico nessas escolas.

Parente (2014a) sistematizou pesquisas e experiências sobre a multisseriação em países desenvolvidos e em desenvolvimento, por meio de uma revisão da literatura internacional, analisando suas opções político-pedagógicas. A conclusão da autora é que no caso brasileiro a multisseriação é resultado de uma necessidade e não uma opção pedagógica.

Em outro estudo, Parente (2014b) analisa os aspectos da organização da escolarização em multisséries, a partir da análise estatística de informações disponibilizadas pelo Instituto Nacional de
Estudos e Pesquisas Educacionais Anísio Teixeira (Inep) e de pesquisas realizadas com professores de escolas públicas de Sergipe. A pesquisa mostrou que a organização da escolarização em multisséries possui diferentes formas e o pressuposto central é a junção de anos/séries. Com relação às concepções e às práticas de professores que atuam em turmas multisseriadas, ficou evidenciado que o trabalho docente está engessado por determinações externas e por barreiras administrativas, inibindo novas reflexões e práticas que rompam com as lógicas tradicionais da seriação, permeadas de elementos excludentes.

\section{O currículo das escolas de campo}

Uma das funções dos currículos de educação do campo, como refere Arroyo (2012b, p. 237), é a de "dar centralidade política e pedagógica ao direito da infância e da adolescência, dos jovens e dos adultos do campo a se conhecerem nessa especificidade histórica e de garantir o seu direito a se reconhecerem nesses processos de segregação e inferiorização".

O tema do currículo nas escolas de campo esteve presente em $8 \%(n=3)$ dos 38 artigos. O estudo de Antonio e Lucini (2007) destaca a importância da educação libertadora, proposta pelo educador Paulo Freire, na construção da Educação do Campo, que juntamente com outras práticas sociais e políticas busca uma transformação social. Os autores resgatam algumas questões históricas da constituição de práticas educativas, que emergem das necessidades de diferentes grupos sociais em acessar a educação, privilegiando a educação popular como uma das matrizes pedagógicas constituintes da educação do campo, e que são tomadas como iniciativas construídas para superar modelos organizacionais e didáticos no currículo escolar.

Thiesen e Oliveira (2012) analisaram a produção teórica dos pesquisadores Roseli Salete Caldart e José Miguel Arroyo, que discutem educação do campo a partir de teorias curriculares. Os autores verificaram um vínculo entre as propostas pedagógicas dos movimentos sociais do campo com as teorias curriculares, porém não há explicita aproximação dessas propostas com Paulo Freire e com as perspectivas críticas de currículo. 
Ribeiro e Paraíso (2012) analisaram as questões curriculares da educação do campo a partir de uma verificação de artigos sobre educação do campo no Brasil em sete revistas de Educação no período de 1987 a 2009 e dos trabalhos sobre a temática apresentados na ANPEd e notaram que há uma polêmica na dicotomia campo-cidade e sobre a necessidade ou não de currículos diferenciados para a população do campo.

\section{O desenvolvimento rural e econômico e o desenvolvimentismo}

O tema do desenvolvimento e suas variantes - o desenvolvimentismo, o desenvolvimento econômico e o desenvolvimento rural - foram abordados em três dos 38 artigos analisados.

A pesquisa de Marschner (2011) verificou como se reconstruiu sociologicamente o "espaço rural" em "campo", elencando alguns aspectos que evidenciam essa reordenação epistêmica. O autor mostra que o "campo" é um lugar onde surgem novas perspectivas de socialização. Na sua visão, epistemologicamente, a Educação do Campo tem o desafio de construir o conhecimento na diversidade.

A pesquisa de Hidalgo (2012) relacionou o desenvolvimentismo ao papel dos organismos internacionais e aos projetos educativos no país nos anos de 1950 e de 1990, em razão de ambos terem sido impulsionados por organismos internacionais e com o propósito de adequarem os sistemas de ensino às demandas econômicas e sociais. A autora apresenta a existência de elementos de continuidade entre as propostas de educação rural realizadas nos anos de 1950 - quando a modernização da cultura das populações e das técnicas agrícolas foram tomadas como estratégias de obtenção dos benefícios sociais e controle dos camponeses - e o Programa ProJovem Campo - Saberes da Terra, implementado pelo Ministério da Educação, a partir dos anos de 1990, em que a ênfase na redução da pobreza e preservação do meio ambiente são postas como condições para o desenvolvimento econômico, na proposta do desenvolvimento sustentável, em que o protagonismo dos movimentos sociais do campo é enfatizado.

Cêa, Silva e Silva (2014) objetivaram identificar ideias e argumentos que predominam em estudos sobre educação do campo e desenvolvimento econômico, e quais aspectos dessa relação podem ser destacados na realidade alagoana. As autoras realizaram um levantamento bibliográfico em teses e dissertações disponíveis no banco de dados da Capes, além de utilizarem dados sobre assentamentos rurais, e constataram uma escassez de trabalhos sobre a educação em áreas rurais no estado. Os dados encontrados mostram que o acesso à educação formal ainda é um problema social para os assentamentos alagoanos, sobretudo na região do sertão.

\section{O ensino de ciências na perspectiva da Educação do Campo}

O ensino de ciências na Educação do Campo deve contemplar indistintamente os diferentes saberes populares e científicos, tendo como ponto de partida a realidade dos estudantes, as práticas das tradições camponesas e as problemáticas de sua comunidade. Essa temática também foi objeto de estudo em três artigos que discutiram o ensino de ciências como conteúdos específicos de disciplinas em escolas no campo.

Cruz e Szymanski, (2012) abordam a necessidade de um trabalho pedagógico no ensino de matemática na modalidade Educação do Campo. As autoras partiram das Diretrizes Curriculares da Educação do Campo para apresentar os pontos principais do desenvolvimento da Metodologia da Mediação Dialética, que possibilita estabelecer relações entre os diferentes saberes do aluno e do professor de forma que o aluno possa superar seu conhecimento imediato sobre o mundo, pelos conhecimentos matemáticos historicamente construídos pelo homem. Nesse contexto, as autoras defendem um trabalho diferenciado, que tome como ponto de partida o conhecimento do aluno e permita a sua ampliação de tal forma que os conhecimentos matemáticos adquiridos sejam realmente úteis em sua vivência de cidadão.

Por sua vez, o artigo de Monteiro, Cruz, e Alves (2012) apresenta parte dos resultados de uma pesquisa que focou a perspectiva dos pais sobre o ensino e a aprendizagem de Matemática nos anos iniciais do Ensino Fundamental em escolas rurais do Agreste de Pernambuco. As análises sugerem 
ambivalências nas falas dos participantes; por um lado, os pais consideraram as aprendizagens, a partir de uma variedade de recursos materiais, humanos e culturais, e, por outro, prevaleceram concepções tradicionais do que sejam o ensino e a aprendizagem de Matemática. $\mathrm{O}$ estudo se insere no debate sobre a reconceitualização do que se compreende como rural, cujos estereótipos que ainda persistem estão associados a um lugar atrasado, de pessoas ignorantes e com dificuldades financeiras, a despeito das mudanças que ocorreram em diversas áreas rurais do Brasil.

O artigo de Crepalde e Aguiar Júnior (2014) examinou os sentidos produzidos ao conceito de energia por estudantes de curso de licenciatura do campo, em narrativas por eles produzidas na atividade de encerramento de uma sequência didática forjada em uma perspectiva de educação intercultural. A produção escrita das narrativas foi marcada pela atitude ativa e responsiva dos estudantes ao demonstrar, especialmente, relações de "entrelaçamentos" entre as palavras alheias (da ciência escolar) e as suas próprias, o que traz implicações para a pesquisa e a prática educativa, especialmente para o ensino de ciências.

\section{Trabalho e educação no contexto da Educação do Campo}

A relação intrínseca entre trabalho e educação está presente nas lutas dos movimentos sociais do campo. Dois artigos analisam essa relação presente na profissionalização dos sujeitos do campo.

O artigo de Vendramini (2007) trata do trabalho no campo como expressão da desigualdade social e da oposição de classe, que se manifesta nas diversas formas de produção de atividades e de sujeitos que vivem, trabalham ou investem no campo. A autora também enfoca a educação do campo, seus avanços em relação à educação rural, sua presença nas políticas educacionais e sua abrangência para além do espaço escolar; e, por último, a valorização que a educação ganha com os movimentos sociais do campo, que passam a defender uma educação articulada com a criação de condições materiais para a vida no campo. O estudo mostra a importância do processo educativo articulado com a criação de condições materiais para a vida no campo. Deste modo, "a defesa de uma educação do campo tem como sustentação o reconhecimento de uma realidade de trabalhadores e trabalhadoras que têm resistido para continuar produzindo sua vida no espaço rural" (VENDRAMINI, 2007, p. 129).

O estudo de Gonçalves e Silva (2011) parte do conceito de trabalho como princípio educativo norteador do desenvolvimento sustentável da agricultura familiar. As autoras pontuam essa discussão em torno da questão colocada de como se constitui a separação histórica entre trabalho e educação. $\mathrm{O}$ artigo discorre sobre o significado do trabalho e sobre a relação educação e trabalho, resgatando o histórico do ensino agrícola no Brasil e apresentando algumas das novas diretrizes do Ministério da Educação para o ensino agrícola no país. Por último, as autoras apontam como um projeto de educação popular pode ser estratégico para o desenvolvimento sustentável do campo.

\section{Movimentos sociais e juventude}

Como refere Pontes (2012, p. 726), “os movimentos sociais do campo, como sujeitos coletivos de direitos e políticas, expressam e reafirmam a capacidade transformadora dos homens e mulheres do campo, quando se movimentam em marchas e ações coletivas buscando um objetivo comum", e instituindo, "de forma autêntica, novos direitos, construindo na prática experiências transformadoras".

Entre os 38 artigos analisados, dois abordaram a temática dos movimentos sociais no contexto da educação do campo e um a temática da juventude.

Hage e Oliveira (2011) apresentam uma cartografia da diversidade socioterritorial nas áreas rurais da Amazônia Paraense, explicitando as territorialidades dos rios, das colônias rurais, dos assentamentos, das reservas extrativistas, dos quilombos e das áreas indígenas. A partir disso, estabelecem relações entre território, políticas públicas e educação do campo no contexto socioterritorial da Amazônia Paraense.

Apoiados no referencial teórico-metodológico bakhtiniano, especialmente na teoria da linguagem, Verdério e Brotto (2011) analisaram as palavras de ordem: "Educação do campo: direito nosso; dever do Estado!", as quais expressam a ação dos 
Movimentos Sociais Populares do Campo no Brasil na luta por uma educação do campo. A partir da análise, os autores mostraram que os signos são produzidos pelos povos do campo e refletem a compreensão da realidade, ou seja, "o reposicionamento dos sujeitos na luta de classe e na própria forma de fazer garantir o seu direito à educação não ocorre sem uma conscientização dos trabalhadores sobre as contradições expressas, inclusive, por meio das políticas sociais" (VERDÉRIO; BROTTO, 2011, p. 1012).

O estudo de Rossi e colaboradores (2014) problematiza a necessidade de discussão das conflitualidades da questão agrária junto à juventude do campo. Na visão dos autores, essa necessidade se justifica em razão de dois argumentos: o reconhecimento contínuo e coletivo da união e do princípio educativo na mobilização e resistência camponesa e, também, o ato permanente do pesquisador em conhecer a realidade camponesa num esforço em prol da efetiva pesquisa educacional do campo. Isso implica em entender o conceito de conflitualidade e de educação do campo enquanto prática intrínseca à pesquisa educacional no campo.

\section{Considerações finais}

O estudo realizado apresentou um panorama da produção científica sobre "Educação do Campo" a partir do ponto de vista de pesquisadores que refletiram sobre esse tema e publicaram artigos em periódicos científicos disponíveis em bibliotecas eletrônicas no período compreendido entre 2007 e 2015. A análise dos artigos selecionados fornece um estado da arte da produção acadêmica recente, contribuindo para ampliar a compreensão do conceito de Educação do Campo, a história das lutas dos movimentos sociais por uma educação que atenda às demandas e necessidades dos sujeitos do campo, bem como as políticas públicas e a formação de educadores do campo.

Finalmente, ao apresentar a distribuição temporal e as autorias desses estudos, e as temáticas privilegiadas na agenda de pesquisas acadêmicas de acordo com os periódicos que publicaram os artigos analisados, foi possível verificar que o tema da Educação do Campo ainda é um tema recente, que merece maiores investimentos na agenda de pesquisas acadêmicas.

\section{REFERÊNCIAS}

ANTONIO, C. A.; LUCINI, M. Ensinar e aprender na educação do campo: processos históricos e pedagógicos em relação. Cadernos CEDES, Campinas, v. 27, n. 72, p. 177-19, ago. 2007.

ARROYO, M. G. Diversidade. In: CALDART, R. S. et al (Org.). Dicionário da Educação do Campo. São Paulo: Expressão Popular, 2012a. p. 231-238.

. Formação de educadores do campo. In: CALDART, R. S. et al (Org.). Dicionário da Educação do Campo. São Paulo: Expressão Popular, 2012b. p. 361-367.

BEZERRA, M. C. S.; BEZERRA NETO, L.; LIMA, E. N. Programa Escola Ativa: de que educação para o trabalhador do campo estamos falando? In: BEZERRA NETO, L.; BEZERRA, M. C. S. (Org.). Educação para o campo em discussão: subsídios para o Programa Escola Ativa. São José: Premier, 2011. p. 19-42.

BEZERRA NETO, L.; BEZERRA, M. C. S. Educação do Campo: referenciais teóricos em discussão. In: BEZERRA NETO, L.; BEZERRA, M. C. S. (Org.). Educação para o campo em discussão: subsídios para o Programa Escola Ativa. São José: Premier, 2011. p. 101-120.

BITTAR, M.; SILVA, M. R.; HAYASHI, M. C. P. I. Produção científica em dois periódicos da área de educação. Avaliação (Unicamp), Campinas, v. 16, p. 193-213, 2011.

BRASIL. Ministério do Desenvolvimento Agrário. Instituto Nacional de Colonização e Reforma Agrária. Programa Nacional de Educação na Reforma Agrária - PRONERA: manual de operações. Brasília, DF, 2004.

. Decreto $\mathrm{n}^{\circ} 7.352$, de 4 de novembro de 2010. Dispõe sobre a política de educação do campo e o Programa Nacional de Educação na Reforma Agrária -PRONERA. Brasília, DF, 2010. Disponível em: <http:// www.planalto.gov.br>. Acesso em: 07 abr. 2013. 
CALDART, R. S. Educação do campo. In: CALDART, R. S. et al (Org.). Dicionário da Educação do Campo. São Paulo: Expressão Popular, 2012. p. 259- 267.

CALDART, R. S. et al (Org.). Dicionário da Educação do Campo. São Paulo: Expressão Popular, 2012.

CASAGRANDE, N. A questão agrária e a formação do educador do campo no século XXI: as contribuições da Pedagogia da Terra. Revista Diálogo Educacional, Curitiba, v. 8, n. 25, p. 765-785, dez. 2008.

CAVALCANTE, L. O. H. Das políticas ao cotidiano: entraves e possibilidades para a educação do campo alcançar as escolas no rural. Ensaio: Avaliação e Políticas Públicas em Educação, v. 18, n. 68, p. 549-564, set. 2010.

CÊA, G. S. dos S.; SILVA, C. F. da; SILVA, E. J. da. Educação do campo e desenvolvimento econômico em Alagoas: problematizando a escassa pesquisa e mapeando a situação. Revista de Educação Pública, Cuiabá, v. 23, n. 53, p. 595-613, ago. 2014. Suplemento 2.

CORREIA, R. A. C.; ROCHA, S. A. da. Formar-se professora para a educação do/no campo: percepções de licenciandas do campo em memoriais de formação. Revista de Educação, Campinas, v. 18, n. 3, p. 355-366, dez. 2013.

CREPALDE, R. dos S.; AGUIAR JÚNIOR, O. G. de. Abordagem intercultural na educação em ciências: da energia pensada à energia vivida. Educação em Revista, Belo Horizonte, v. 30, n. 3, p. 43-61, set. 2014.

CRUZ, J. Z. da S.; SZYMANSKI, M. L. S. O ensino da matemática nas escolas do campo por meio da metodologia da mediação dialética. Práxis Educativa, Ponta Grossa, PR, v. 7, n. 2, p. 445-465, dez. 2012.

CURY, C. R. J. Políticas inclusivas e compensatórias na educação básica. Cadernos de Pesquisa (Fundação Carlos Chagas), São Paulo, v. 35, p. 11-32, 2005.

D'AGOSTINI, A. A educação do campo na educação brasileira: contradições e perspectivas. Educação, Santa Maria, RS, v. 37, n. 3, p. 453-467, dez. 2012.

D’AGOSTINI, A.; TAFFAREL, C. Z.; SANTOS JÚNIOR, C. L. Escola Ativa. In: CALDART, R. S. et al (Org.). Dicionário da Educação do Campo. São Paulo: Expressão Popular, 2012. p. 315-326.

EDUC@. Publicações online de Educação. Disponível em:<http://educa.fcc.org.br/>. Acesso em: 20 mai. 2015.

FERNANDES, B. M. Brasil: 500 anos de luta pela terra. Cultura Vozes, v. 93, n. 2, p. 1- 12, 1999.

GEHRKE, M. Formação de infâncias ledoras-escrevedoras: desafios da Escola do Campo. Educação, Santa Maria, RS, v. 34, n. 1, p. 195-218, abr. 2009.

GONÇALVES, M. A.; SILVA, M. A. da. Trabalho e educação: o ensino profissional e o desenvolvimento rural. Roteiro (UNOESC), Videira, SC, v. 36, n. 2, p. 347-362, jul. 2011.

GUHUR, D. M. P.; SILVA, I. M. de S. Educação do campo: primeiras aproximações. Roteiro (UNOESC), Videira, SC, v. 34, n. 2, p. 129-144, dez. 2009.

HAGE, S. A. M. Transgressão do Paradigma da (Multi)Seriação como referência para a construção da Escola Pública do Campo. Educação e Sociedade, Campinas, SP, v. 35, n. 129, p. 1165-1182, dez. 2014.

HAGE, S. M.; OLIVEIRA, L. M. M. de. Território, políticas públicas e educação do campo na Amazônia Paraense: o protagonismo dos movimentos sociais em debate. Revista de Educação Pública, Cuiabá, v. 20, n. 42, p. 91-107, jan. 2011.

HAYASHI, M. C. P. I. et al. Protocolo para coleta de dados bibliométricos em bases de dados, 2011. Mimeografado.

HIDALGO, A. M. Projetos educativos para as populações do campo nos anos de 1950 e ProJovem Campo - Saberes da Terra: desenvolvimentismo e proposições dos organismos internacionais. Revista Brasileira de História da Educação, Maringá, PR, v. 12, n. 2, p. 239-266, maio 2012.

JESUS, S. M. S. A. de. Educação do campo nos governos FHC e Lula da Silva: potencialidades e limites de acesso à educação no contexto do projeto neoliberal. Educar em Revista, Curitiba, n. 55, p. 167-186, mar. 2015.

MACHADO, I. F. Crítica e autocrítica: avaliação participativa em escolas do campo do estado de Mato Grosso. Educação: Teoria e Prática, Rio Claro, SP, v. 20, n. 35, p. 57-69, dez. 2010.

MARCON, T. Políticas de educação do campo: avanços e desafios. Práxis Educativa, Ponta Grossa, PR, v. 7, n. 
1, p. 85-105, jun. 2012.

MARSCHNER, W. Lutando e ressignificando o rural em campo: notas epistemológicas. Interações, Campo Grande, MS, v. 12, n. 1, p. 41-52, jun. 2011.

MOLINA, M. C. A contribuição do PRONERA na construção de políticas públicas de educação do campo e desenvolvimento sustentável. 2003. 146f. Tese (Doutorado em Desenvolvimento Sustentável) - Universidade de Brasília (UnB), Brasília, DF, 2003.

(Org.) Educação do campo e pesquisa II: questões para reflexão. Brasília, DF: MDA/MEC, 2010.

. Expansão das licenciaturas em Educação do Campo: desafios e potencialidades. Educar em Revista, Curitiba, n. 55, p. 145-166, mar. 2015.

Bibliografia comentada. Em Aberto, Brasília, DF, v. 24, n. 85, p. 165-177, abr. 2011.

. Legislação educacional do campo. In: CALDART, R. S. et al (Org.). Dicionário da Educação do Campo. São Paulo: Expressão Popular, 2012. p. 453-459.

MOLINA, M. C.; ABREU, H. C. de F. Apresentação. Em Aberto, Brasília, DF, v. 24, n. 85, p. 11-14, abr. 2011.

MONTEIRO, C. E. F.; CRUZ, F. M. L.; ALVES, I. M. O que dizem os pais sobre o ensino e a aprendizagem de matemática em escolas rurais. Roteiro (UNOESC), Videira, SC, v. 37, n. 1, p. 23-50, jun. 2012.

NASCIMENTO, C. G. do. A teoria crítica de Gramsci nas pedagogias alternativas de educação do campo. Linhas Críticas, Brasília, DF, v. 13, n. 25, p. 185-202, dez. 2007.

PALUDO, C.; SILVEIRA, D. M. Contribuições para a história da educação infantil do campo no Brasil. Contrapontos, Itajaí, SC, v. 14, n. 1, p. 170-185, abr. 2014.

PARENTE, C. da M. D. Escolas multisseriadas: a experiência internacional e reflexões para o caso brasileiro. Ensaio: Avaliação e Políticas Públicas em Educação, Rio de Janeiro, v. 22, n. 82, p. 57-88, jan. 2014a.

PARENTE, C. da M. D. Perfil, concepções e práticas pedagógicas de professores que atuam em turmas multisseriadas de escolas públicas de Sergipe. Revista Brasileira de Estudos Pedagógicos, Brasília, DF, v. 95, n. 241, p. 676-695, dez. 2014b.

PONTES, M. L. de. Sujeitos coletivos de direito. In: CALDART, R. S. et al (Org.). Dicionário da Educação do Campo. São Paulo: Expressão Popular, 2012. p.726-730.

RANGEL, M.; CARMO, R. B.do. Da educação rural à educação do campo: revisão crítica. Revista da FAAEBA: Educação e Contemporaneidade, Salvador, v. 20, n. 36, p. 205-214, dez. 2011.

RIBEIRO, M. Educação Rural. In: CALDART, R. S. et al (Org.). Dicionário da Educação do Campo. São Paulo: Expressão Popular, 2012a. p. 295-301.

. Educação do campo: embate entre Movimento Camponês e Estado. Educação em Revista, Belo Horizonte,

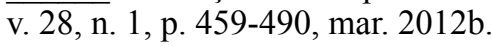

Política educacional para populações camponesas: da aparência à essência. Revista Brasileira de Educação, v. 18, p. 669-691, 2013a.

Formação de educadores de jovens e adultos do campo: quase tudo por fazer. Perspectiva, Florianópolis,

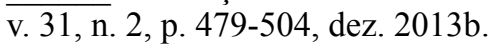

. Reforma agrária, trabalho agrícola e educação rural: desvelando conexões históricas da educação do campo. Educação e Pesquisa, São Paulo, v. 41, n. 1, p. 79-100, mar. 2015.

RIBEIRO, V.; PARAÍSO, M. A. A produção acadêmica sobre educação do campo no Brasil: currículos e sujeitos demandados. Educação, Porto Alegre, v. 35, n. 2, p. 169-180, ago. 2012.

RIGOLIN, C. C. D.; HAYASHI, C. R. M.; HAYASHI, M. C. P. I. Métricas da participação feminina na ciência e na tecnologia no contexto dos INCTs: primeiras aproximações. Liinc em Revista, v. 9, p. 143-170, 2013.

ROSSI, R. et al. Educação do campo e juventude: problematizações a partir da conflitualidade. Educação, Santa Maria, RS, v. 39, n. 3, p. 605-615, dez. 2014.

SANTOS, C. F.; PALUDO, C.; BASTOS, R. Concepção de Educação do Campo. In: TAFFAREL, C. N. Z. et al. 
(Org.). Cadernos Didáticos sobre educação no campo. Salvador: Universidade Federal da Bahia, 2010. p. 13-70.

SCIELO. Scientific Electronic Library Online. 2015. Disponível em: <http://www.scielo.br/> Acesso em: 20 maio 2015.

SILVA, M. R. da; HAYASHI, C. R. M.; HAYASHI, M. C. P. I. Análise bibliométrica e cientométrica: desafios aos especialistas que atuam no campo. InCID: Revista de Ciência da Informação e Documentação, Ribeirão Preto, SP, v. 2, p. 110-129, 2011.

SOUZA, M. A. de. Educação do campo, desigualdades sociais e educacionais. Educação e Sociedade, Campinas, SP, v. 33, n. 120, p. 745-763, set. 2012.

SOUZA, M. A. de; MARCOCCIA, P. C. de P. Educação do campo, escolas, ruralidades e o projeto do PNE. Revista da FAAEBA: Educação e Contemporaneidade, Salvador, v. 20, n. 36, p. 191-204, dez. 2011.

SOUZA, M. A. de; SANTOS, F. H. T. dos. Educação do campo: prática do professor em classe multisseriada. Revista Diálogo Educacional, Curitiba, v. 7, n. 22, p. 211-227, dez. 2007.

TEIXEIRA, E. S., BERNARTT, M. de L.; TRINDADE, G. A. Estudos sobre pedagogia da alternância no Brasil: revisão de literatura e perspectivas para a pesquisa. Educação e Pesquisa, São Paulo, v. 34, n. 2, p. 227-242, ago. 2008.

THIESEN, J. da S.; OLIVEIRA, M. A. de. O lugar do currículo na/da educação do campo no Brasil: aproximações e teorias curriculares. Revista de Educação Pública, Cuiabá, v. 21, n. 45, p. 13-28, abr. 2012.

VENDRAMINI, C. R. Educação e trabalho: reflexões em torno dos movimentos sociais do campo. Cadernos CEDES, Campinas, SP, v. 27, n. 72, p. 121-135, ago. 2007.

VERDÉRIO, A. BROTTO, I. J. de O. Educação do campo: materialidade da luta e signos discursivos. Revista Diálogo Educacional, Curitiba, v. 11, n. 34, p. 997-1014, dez. 2011.

Recebido em: 20.02.2016

Aprovado em: 19.07.2016 